\title{
The Association Between Fibromyalgia and Mechanical Neck Lesions
}

\author{
Maryam Haghparast ${ }^{1}$, Elham Atabati ${ }^{* 2}$, Vajihollah Raiisi ${ }^{3}$,Ahmadreza Sebzari³, Gholamreza Sharifzadeh ${ }^{4}$ \\ ${ }^{1}$ Valiasr Hospital, Birjand University of Medical Sciences, Birjand, Iran. ${ }^{2}$ Clinical Research Development Unit, Valiasr \\ Hospital, Birjand University of Medical Sciences, Birjand, Iran. ${ }^{3}$ Birjand University of Medical Sciences, Birjand, \\ Iran. ${ }^{4}$ Social Determinants of Health Research Center, Birjand University of Medical Sciences, Birjand, Iran
}

\begin{abstract}
Fibromyalgia is a painful syndrome with a non-joint origin. The disease is of relatively high prevalence and is most common in women and people over 40 years of age.

This case-control study enrolled 35 healthy individuals as the control group and 35 patients with fibromyalgia as the case group. A cervical MRI was performed for all participants, and the graphs were interpreted by a specialist who was blind to the patient group. Lesions were severe in $94.3 \%$ of the case group, $80 \%$ of the controls $(P$ value $>0.05)$. Between the groups, no significant difference was observed in the number of involved surfaces or in mean lesion levels. In the case and control groups, $48.5 \%$ and $92.9 \%$, respectively, had only one lesion. The rates of concurrent lesions in the case and control groups were $51.5 \%$ and $7.1 \%$, respectively $(P$ value $<0.001)$. In $60.6 \%$ of the case group and $17.9 \%$ of the control group, the lesion was severe $(P$ value $=0.001)$. The prevalence of annular tearing and stenosis of the canal was significantly higher in the case group than in the control group $(P$ value $=0.05$ and $P$ value $=0.044$, respectively). However, there was no significant difference between the groups in other lesions. Given the similarity of some of the symptoms in fibromyalgia and mechanical neck lesions, it is crucial to have timely and correct differentiation of these two diseases. Also, these results may suggest that long-term fibromyalgia can potentially exacerbate the symptoms of mechanical neck lesions.
\end{abstract}

Keywords: Fibromyalgia; Hernia; Osteoarthritis; Pain; Mechanical neck lesions

\section{Introduction}

Fibromyalgia is a painful syndrome with a non-joint origin characterized by diffuse pain, fatigue, and sleep disorder. Patients also suffer from depression, anxiety, and stress [1]. Fibromyalgia is one of the most common diseases to involve muscles and affect the life quality and performance of patients [2]. Studies have shown that in the United States, \$16 billion is spent directly and indirectly to provide health services and treat fibromyalgia patients every year [3]. The incidence of the disease varies between $1 \%$ and $1.5 \%$, depending on the time and place, and is more common in women and people above 40 years of age $[4,5]$; it is common with a ratio of $9: 1$ in women than men [6], with a larger occurrence in middle-aged white women [7]. Its prevalence is estimated to range from $0.7 \%$ to $4.7 \%$ in the general population of industrial countries [8].

The disease is the most common cause of diffuse pain in women aged 20 to 55 years, and more than $40 \%$ of the patients visiting a specialist pain center are found to have fibromyalgia [9].

Although biological, genetic, and environmental factors are involved in the development and progression of this syndrome, its etiology is still unknown [10].

In a study conducted in Isfahan in 1999 , about $11 \%$ of the patients referring to a rheumatology clinic were affected by fibromyalgia [7]. Fibromyalgia has a high correlation with other functional and psychological problems [11]; major depressive disorder stands as the most common accompanying psychiatric disorder with an incidence rate of $20-80 \%$ [12]. Due to its non-specific pathology, drug therapies are complicated and often effective only for a short time [13].

The prevalence of fibromyalgia increases with age and is reported to predominantly affect the middle and upper

Personal non-commercial use only.Rheumatology Research Journal. Copyright (C) 2019. All rights reserved

*Corresponding Author: Elham Atabati, Clinical Researsh Development unit, Valiasr Hospital, Birjand University of Medical Sciences, Birjand, Iran, Email: elham1405@yahoo.com

Received: 04 August 2019; Accepted: 11 January 2020 
classes of a community. It affects the life quality of the individual to a significant extent [7]. Chronic pain is one of the most prominent symptoms of this disease, and it significantly affects the individual, familial, and professional life of patients. Symptoms of depression and other psychological problems are associated with increased pain and decreased quality of life in these patients [14].

In 1994, the cost of treatment and disability caused by osteoarthritis in the United States amounted to \$15.5 million [15]. Fibromyalgia syndrome is not diagnosed with current clinical trials, but only by a physician based on the history of the disease and a clinical examination based on the American College of Rheumatology (ACR) criteria [7].

Arthritis of the apophatic joints is common in the upper cervical spine, namely, $\mathrm{C} 2-\mathrm{C} 3$ and $\mathrm{C} 3-\mathrm{C} 4$. Damage to these joints is sometimes accompanied by capsular and ligation disorders. Osteophytes of these joints may also stimulate the nerve root or press the nervous system around the vertebral artery, causing the stimuli and symptoms of the nervous system [16]. Cervical arthritis is usually silent, sometimes characterized by limited painless movements during daily activities, such as looking to the rear during driving, and sometimes by various painful syndromes $[17$, 18]. There are several therapies for fibromyalgia; however, their real impact is not known, and more emphasis is placed on a multi-faceted treatment. Therapeutic protocols that entail reduced nervous pressure, regular exercise, and patient training can be useful in relieving symptoms. Nevertheless, until now, no specific and effective therapy has been found to treat the disease [19]. The current study was designed to investigate the relationship between the prevalence of fibromyalgia and mechanical neck lesions in Birjand city.

\section{Materials and Methods}

This case-control study used convenience sampling to recruit participants from among patients referring to the Vali-e-Asr Hospital Specialized Clinic of Birjand with fibromyalgia pain during the first six months of 2018. They were included as the case group after they had been examined for inclusion and exclusion criteria. From among companions of the patients, subjects determined to be healthy according to the revised fibromyalgia impact questionnaire were recruited as the control group. Inclusion criteria comprised the willingness to participate in the study and the minimum age of 20 years; exclusion criteria included a reluctance to cooperate or participate in the study and candidature for surgery for mechanical neck lesions.

Patients were enrolled in the study based on the physician's diagnosis and patient satisfaction. Ethical code is Ir.bums.REC.1397.4.

The sample size was estimated to be $n=29$ per group. Ultimately, 35 people were enrolled in each group. The collected data was analyzed using SPSS software, version 23, t-test, chi-square test, and Fisher exact test. The significance level was set at $P$ value $<0.05$.

Disease diagnoses were based on the criteria set by the American College of Rheumatology. All participants were selected using the convenience sampling method. The groups were matched for age and gender, and all participants underwent an MRI.

At the beginning of the study, all patients were presented with a summary of the study goals in simple language. If they agreed and signed written informed consent forms, they were enrolled in the study. No cost was incurred by the patients for the implementation of the project. All Helsinki's provisions and 31 moral codes were observed in the study.

Data collection tools consisted of the findings of clinical graphs and a researcher-made questionnaire. The graphs were interpreted by a specialist who was blind to the patient group. The protocol was approved before being implemented by the Ethics Committee of Birjand University of Medical Sciences.

\section{Results}

This study enrolled 35 patients as the fibromyalgia group; $60 \%$ of the patients had severe $(\mathrm{N}=21), 28.6 \%$ had moderate $(\mathrm{N}=10)$, and $11.4 \%$ had mild $(\mathrm{N}=4)$ fibromyalgia, and 35 people were enrolled as healthy individuals (Table 1).

Table 1. Comparison of the frequency distribution of gender, education level, and occupation in the two groups

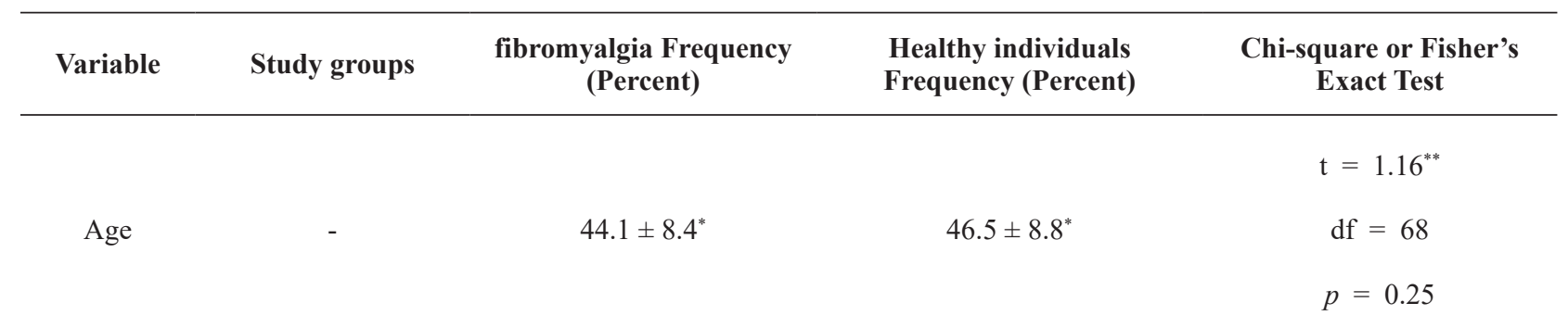




\begin{tabular}{|c|c|c|c|c|}
\hline Variable & Study groups & $\begin{array}{c}\text { fibromyalgia Frequency } \\
\text { (Percent) }\end{array}$ & $\begin{array}{l}\text { Healthy individuals } \\
\text { Frequency (Percent) }\end{array}$ & $\begin{array}{c}\text { Chi-square or Fisher's } \\
\text { Exact Test }\end{array}$ \\
\hline \multirow{4}{*}{ Gender } & & & & $\chi^{2}=2.12$ \\
\hline & Male & $5(14.3)$ & $10(28.6)$ & \\
\hline & Female & $30(85.7)$ & $25(78.4)$ & \\
\hline & & & & $p=0.14$ \\
\hline \multirow{3}{*}{$\begin{array}{l}\text { Education } \\
\text { level }\end{array}$} & Illiterate & $3(8.6)$ & $2(5.7)$ & Fisher's Exact \\
\hline & Secondary school & $11(31.4)$ & $20(57.1)$ & $\chi^{2}=4.69$ \\
\hline & Tertiary school & $21(60)$ & $13(37.2)$ & $p=0.11$ \\
\hline \multirow{5}{*}{ Occupation } & Housewife & $19(54.3)$ & $16(45.7)$ & \\
\hline & Employee & $12(34.3)$ & $16(45.7)$ & Fisher's Exact \\
\hline & Student & $1(2.9)$ & $0(0)$ & $\chi^{2}=4.33$ \\
\hline & Self-employed & $1(2.9)$ & $3(8.6)$ & $p=0.31$ \\
\hline & Worker & $2(5.7)$ & $0(0)$ & \\
\hline
\end{tabular}

*: mean \pm sd

$* *$ : t-test

As can be seen in Table 1, the two groups were similar in terms of age, and no significant differences were found between the two groups in the distribution of gender, education level, or occupation frequency. The similarity of the two groups in terms of these variables was confirmed.
As shown in Table 2, 94.3\% of the individuals in the fibromyalgia group and $80 \%$ of the healthy individuals had severe lesions, although the difference between the groups was not significant.

Table 2. Frequency distribution of the severity of involvement in the groups

\begin{tabular}{ccccc}
\hline $\begin{array}{c}\text { Group } \\
\text { Severity of involvement }\end{array}$ & $\begin{array}{c}\text { Fibromyalgia } \\
\text { Frequency (Percent) }\end{array}$ & $\begin{array}{c}\text { Healthy individuals } \\
\text { Frequency (Percent) }\end{array}$ & $\begin{array}{c}\text { Total } \\
\text { Frequency (Per- } \\
\text { cent) }\end{array}$ & Chi-square test \\
Severe & $33(94.3)$ & $28(80)$ & $61(87.1)$ & $\chi^{2}=4.20$ \\
Mild & $2(5.7)$ & $7(20)$ & $9(12.9)$ & $p=0.08$ \\
Total & $35(100)$ & $35(100)$ & $70(100)$ & \\
\hline
\end{tabular}

In the table above, the severity of involvement refers to the type of lesions including stenosis canal, disk protrusion, and annular tearing. A mild lesion involves spondylosis, disc dehydration, and disc herniation. A severe lesion is grade III, and a mild lesion is either grade I or II.
As seen in Table 3, 60.6\% of the lesions in individuals with severe lesions in the fibromyalgia group were of the severe lesion grade. In healthy individuals, only $17.9 \%$ had a lesion grade of severe. The difference between the groups was significant $(P$ value $=0.001)$. 
Table 3. Frequency distribution of the severe grade of involvement in the two groups

\begin{tabular}{cccc}
\hline $\begin{array}{c}\text { Group } \\
\text { Grade of involvement }\end{array}$ & $\begin{array}{c}\text { Fibromyalgia } \\
\text { Frequency (Percent) }\end{array}$ & $\begin{array}{c}\text { Healthy individuals } \\
\text { Frequency (Percent) }\end{array}$ & $\begin{array}{c}\text { Total } \\
\text { Frequency (Percent) }\end{array}$ \\
\hline Severe & $20(60.6)$ & $5(17.9)$ & $25(41)$ \\
Mild & $13(39.4)$ & $23(82.1)$ & $36(59)$ \\
Total & $33(100)$ & $28(100)$ & $61(100)$ \\
\hline
\end{tabular}

As seen in Table 4, there was no significant difference between the fibromyalgia and healthy groups in the number of involved surfaces. Moreover, the means of involved surfaces in the fibromyalgia and healthy groups were 2.06 \pm 0.93 and $2.14 \pm 0.65$, respectively. The difference was not significant $(P$ value $=0.69, \mathrm{t}=0.29)$.

Table 4. Comparison of the frequency distribution of involved surfaces in the two groups

\begin{tabular}{ccccc}
\hline $\begin{array}{c}\text { Group } \\
\text { Number of involved surfaces }\end{array}$ & $\begin{array}{c}\text { Fibromyalgia } \\
\text { Frequency (Percent) }\end{array}$ & $\begin{array}{c}\text { Healthy individuals } \\
\text { Frequency (Percent) }\end{array}$ & $\begin{array}{c}\text { Total } \\
\text { Frequency (Percent) }\end{array}$ & Fisher's Exact test \\
\hline One surface & $11(33.3)$ & $4(14.3)$ & $15(24.6)$ \\
Two surfaces & $11(33.3)$ & $16(57.1)$ & $27(44.3)$ & Fisher $=5.43$ \\
Three surfaces & $9(27.3)$ & $8(28.6)$ & $17(27.9)$ & $p=0.12$ \\
Four surfaces & $2(6.1)$ & $0(0)$ & $61(100)$ & \\
Total & $33(100)$ & $28(100)$ & & \\
\hline
\end{tabular}

As seen in Table 5, the mean number of lesions in the fibromyalgia and healthy groups were $48.5 \%$ and $92.9 \%$, respectively. The difference was significant $(P$ value $<0.001)$.

The distribution of the number of lesions denotes the frequency distribution of concurrent lesions in the two groups.
Based on the data in Table 6, annular tearing and canal stenosis were significantly more prevalent in the case than the control group, but there was no significant difference between the groups for other lesions.

Table 5. Comparison of the frequency distribution of lesions in the two groups

\begin{tabular}{ccccc}
\hline $\begin{array}{c}\text { Group } \\
\text { Number lesions }\end{array}$ & Frequency (Percent) & Frequency (Percent) & Frequency (Percent) & Fisher's Exact test \\
\hline One lesion & $16(48.5)$ & $26(92.9)$ & $42(68.9)$ & \\
Two lesions & $16(48.5)$ & $2(7.1)$ & $18(29.5)$ & Fisher $=14.44$ \\
Three lesions & $1(3)$ & $8(28.6)$ & $17(27.9)$ & $p$ \\
Four lesions & $2(6.1)$ & $0(0)$ & $1(1.6)$ & 001 \\
Total & $33(100)$ & $28(100)$ & $61(100)$ & \\
\hline
\end{tabular}


Table 6. Comparison of the frequency distribution of types of lesions in the two groups

\begin{tabular}{|c|c|c|c|c|}
\hline \multicolumn{2}{|c|}{$\begin{array}{c}\text { Group } \\
\text { Type of lesion }\end{array}$} & \multirow{2}{*}{$\begin{array}{c}\text { Fibromyalgia } \\
\text { Frequency (Percent) }\end{array}$} & \multirow{2}{*}{$\begin{array}{c}\text { Healthy individuals } \\
\text { Frequency (Percent) } \\
6(1.17)\end{array}$} & \multirow{2}{*}{$\begin{array}{c}\text { Chi-square test } \\
\chi^{2}=0.094\end{array}$} \\
\hline Sorduloci & Positive & & & \\
\hline Sponaylosis & Negative & $28(80)$ & $29(9.82)$ & $p=0.76$ \\
\hline \multirow{2}{*}{ Disk Dehydration } & Positive & $14(40)$ & $19(4.53)$ & $\chi^{2}=1.43$ \\
\hline & Negative & $21(60)$ & $16(7.45)$ & $p=0.23$ \\
\hline \multirow{2}{*}{ Disk Protrusion } & Positive & $29(9.82)$ & $24(6.68)$ & $\chi^{2}=1.94$ \\
\hline & Negative & $6(1.17)$ & $11(4.31)$ & $p=0.16$ \\
\hline \multirow{2}{*}{ Disk Dehydration } & Positive & $27(1.77)$ & $23(7.65)$ & $\chi^{2}=1.12$ \\
\hline & Negative & $8(9.22)$ & $12(3.34)$ & $p=0.29$ \\
\hline \multirow{2}{*}{ Annular Tearing } & Positive & $7(20)$ & $1(9.2)$ & $\chi^{2}=1.39$ \\
\hline & Negative & $28(80)$ & 14 (1.97) & $p=0.24$ \\
\hline \multirow{2}{*}{ Canal Stenosis } & Positive & $12(3.34)$ & $4(4.11)$ & $\chi^{2}=5.18$ \\
\hline & Negative & $23(7.65)$ & $31(6.88)$ & $p=0.02$ \\
\hline
\end{tabular}

\section{Discussion}

This study investigated the relationship between the prevalence of fibromyalgia and mechanical neck lesions. Patients with fibromyalgia were treated with analgesics and SSIRs before referring to CS). Based on the results, the prevalence of severe cervical lesions was greater in subjects with fibromyalgia than in healthy subjects. Furthermore, the risk of concurrent lesions was more substantial in individuals with fibromyalgia than in the healthy participants.

According to recent reports, the prevalence of fibromyalgia ranges between $2 \%$ and $8 \%$ [20]. However, according to new fibromyalgia criteria [21], the disease appears to be widespread, and more people are potentially fibromyalgia patients.

Whether afflicted individuals are primarily affected by the disease or have symptoms of a secondary cause, such as chronic pain disorders (e.g., trauma, osteoarthritis, cervical and lumbar discopathic lesions, and chronic diseases, among others).

In terms of pathophysiology, fibromyalgia can be considered an abnormal response without a secondary limitation to a kind of neurotic stimulation, such that patients afflicted with this disease are at lower thresholds for acoustic and mechanical stimuli [21].

According to the results of the current study, most of the participants with fibromyalgia were rated as type I (i.e. Symptom Severity Score $>5$ and Widespread Pain Index $>$
7). This finding suggests that the patients reported a minimum of seven cases out of the 20 types of discomfort associated with fibromyalgia [22].

The results also showed that the fibromyalgia group had cervical lesions with a grade higher than 3; in other words, cervical spine lesions were reported to be the most severe in annular tearing, disk protrusion, and stenosis of the canal. Moreover, the types of severe lesions seen in the fibromyalgia group were greater in number and diversity than those in the healthy group. These findings suggest that the fibromyalgia group in the current study had more severe and more extensive lesions in the cervical vertebrae than the healthy subjects. A noteworthy point in the results of the current study is that possibly, the presence of more severe cervical lesions (localized lesions, according to the general definition) can cause fibromyalgia syndrome, widespread symptoms, and generalized manifestations in the form of fibromyalgia over a long period of time. In the current study, no significant difference in the incidence of cervical spine lesions was seen between the fibromyalgia patients and the healthy population. These results are consistent with those of Guller et al. in 2015 [22].

In a study conducted in 2013 by Brummet et al., fibromyalgia patients were reported to have more severe symptoms than vertebral collateral problems, which is not consistent with the current results. The reason for this difference is attributable to the type of patients investigated in the current study. Considering the social and cultural context and 
age group, subjects in the current study were actively employed members of society. Active people have a higher tolerance to pain, and this may explain why fibromyalgia patients suffer more severe lesions and more typical symptoms. The current study did not cover a large number of patients due to temporal and spatial constraints. More studies should be done to generalize the results.

This study aimed to investigate the relationship between the prevalence of fibromyalgia and mechanical neck lesions. Based on the results, the prevalence of cervical lesions graded as severe in patients with fibromyalgia was $60.6 \%$, which was significantly higher than among the healthy subjects $(17.9 \%)$. Moreover, the probability of concurrent lesions in patients with fibromyalgia was $51.5 \%$, which is higher than that of the healthy subjects $(1.7 \%)$.

\section{Conclusion}

The findings of this study also indicated that local symptoms are important in patients with common pain complaints who meet the fibromyalgia criteria. They should be examined for vertebral lesions, especially in the neck region, so that the golden time for intervention is not lost. Considering the similarity of some of the symptoms of fibromyalgia and mechanical neck lesions, the timely and correct differentiation of these two diseases is critical. The results may also suggest that long-term affliction with fibromyalgia can potentially exacerbate the symptoms of mechanical neck lesions. However, more accurate results require more comprehensive studies in this regard.

The limitation of this study involves the relatively small sample size. This study did not cover a large number of patients due to space and time constraints. Therefore, it is suggested that studies with a larger sample size be conducted.

\section{Acknowledgments}

The authors are grateful to the staff at Vali-Asr Hospital and all the patients who assisted with this study.

\section{Conflict of Interest}

The authors declare no conflicts of interest. 


\section{References}

1. Alok R, Das S, Agarwal G, Salwahan L, Srivastava R Relationship of severity of depression, anxiety and stress with severity of fibromyalgia. Clin Exp Rheumatol 2011;29(6):S70.

2. Verbunt JA, Pernot DH, Smeets RJ. Disability and quality of life in patients with fibromyalgia. Health Qual Life Outcomes 2008;6(1):8. doi: 10.1186/1477-7525-6-8.

3. White J, Hornsby J, Hornsby G, Ullrich I, Briggs P, Yeater R. A pilot study to determine the efficacy of aquatic therapy on functional outcomes in fibromyalgia. Arthritis Rheum 1999;42(9).

4. Lourenço S, Costa L, Rodrigues AM, Carnide F, Lucas R. Gender and psychosocial context as determinants of fibromyalgia symptoms (fibromyalgia research criteria) in young adults from the general population. Rheumatology (Oxford) 2015;54(10):1806-15. doi: 10.1093/rheumatology/kev110.

5. Rusu C, Gee M, Lagacé C, Parlor M. Chronic fatigue syndrome and fibromyalgia in Canada: prevalence and associations with six health status indicators. Health promot chronic dis prev Can 2015;35(1):3-11. doi: 10.24095/ hpcdp.35.1.02

6. Yunus MB. Gender differences in fibromyalgia and other related syndromes. J Gend Specif Med 2002;5(2):42-7.

7. A M. The effect of a home-based training program on reducing symptoms in women with fibromyalgia. Isfahan University 2009.

8. Branco JC, Bannwarth B, Failde I, Carbonell JA, Blotman F, Spaeth M, et al. Prevalence of fibromyalgia: a survey in five European countries. Semin Arthritis Rheum 2010; 39(6):448-53. doi: 10.1016/j.semarthrit.2008.12.003.

9. Goldenberg DL. Diagnosis and differential diagnosis of fibromyalgia. Am J Med 2009;122(12):S14-S21. doi: 10.1016/j.amjmed.2009.09.007.

10. Geoffroy PA, Amad A, Gangloff C, Thomas P. Fibromyalgia and psychiatry: 35 years later... what's new? Presse Med 2012;41(5):455-65. doi: 10.1016/j.1pm.2011.08.008.

11. Wolfe F, Ross K, Anderson J, Russell IJ, Hebert L. The prevalence and characteristics of fibromyalgia in the general population. Arthritis Rheum 1995;38(1):19-28. doi: 10.1002/art.1780380104.

12. Aguglia A, Salvi V, Maina G, Rossetto I, Aguglia E. Fibromyalgia syndrome and depressive symptoms: comorbidity and clinical correlates. J Affect Disord 2011;128(3):26266. doi: 10.1016/j.jad.2010.07.004.

13. Schmidt S, Grossman P, Schwarzer B, Jena S, Naumann J, Walach $H$. Treating fibromyalgia with mindfulness-based stress reduction: results from a 3-armed randomized controlled trial. Pain 2011;152(2):361-9. doi: 10.1016/j. pain.2010.10.043.

14. Parra-Delgado M, Latorre-Postigo JM. Effectiveness of mindfulness-based cognitive therapy in the treatment of fibromyalgia: A randomised trial. Cog Ther Res 2013;37(5):1015-26. doi: 10.1007/s10608-013-9538-z.
15. Anderson JJ, Felson DT. Factors associated with osteoarthritis of the knee in the first national Health and Nutrition Examination Survey (HANES I) evidence for an association with overweight, race, and physical demands of work. Am J Epidemiol 1988;128(1):179-89. doi: 10.1093/oxfordjournals.aje.a114939.

16. Akbari M, Bayat M. Effects of Mechanical Traction on Patients with Mild and Moderate Cervical Osteoarthritis. Razi J Med Sci 2008;14(57):29-40.

17. Moskowitz RW. Clinical and laboratory finding in osteoarthritis. Arthritis Allied Condi 1979:1161-80.

18. Pfirrmann CW, Resnick D. Schmorl nodes of the thoracic and lumbar spine: radiographic-pathologic study of prevalence, characterization, and correlation with degenerative changes of 1,650 spinal levels in 100 cadavers. Radiology 2001;219(2):368-74. doi: 10.1148/radiology219.2.r01ma21368.

19. Sim J, Adams N. Therapeutic approaches to fibromyalgia syndrome in the United Kingdom: a survey of occupational therapists and physical therapists. Eur J pain 2003;7(2):173-80. doi: 10.1016/S1090-3801(02)00095-2.

20. Clauw DJ. Fibromyalgia: a clinical review. JAMA 2014;311(15):1547-55. doi: 10.1001/jama.2014.3266.

21. Plesner KB, Vaegter HB. Symptoms of fibromyalgia according to the 2016 revised fibromyalgia criteria in chronic pain patients referred to multidisciplinary pain rehabilitation: influence on clinical and experimental pain sensitivity. J Pain 2018;19(7):777-86. doi: 10.1016/j. jpain.2018.02.009.

22. Güler M, Aydın T, Akgöl E, Taşpınar Ö. Concomitance of fibromyalgia syndrome and cervical disc herniation. $\boldsymbol{J}$ Phys Ther Sci 2015;27(3):785-9. doi: 10.1589/jpts.27.785. Epub 2015 Mar 31. 
